10.1590/S1414-40772018000300008

Este é um artigo publicado em acesso aberto sob uma licença Creative Commons

https://creativecommons.org/licenses/by-nc/4.0/

\title{
Dez anos de avaliação institucional (2006-2016): o que nos mostra a produção de conhecimento
}

\author{
Raquel Lazzari Leite Barbosa ${ }^{1}$ \\ Rosaria Fátima Boldarine ${ }^{2}$
}

Resumo: O presente artigo é fruto de uma revisão bibliográfica que teve como objetivo identificar aspectos relevantes da produção científica brasileira sobre avaliação institucional, no período de 2006 a 2016, em sete periódicos da área educacional com reconhecida relevância. Foram analisados sessenta e cinco trabalhos. Os resultados demonstraram que o tema avaliação institucional está sendo contemplado em diversos periódicos, com um número considerável de artigos e com diversas abordagens. A proposta é trazer elementos que contribuam com o entendimento das práticas avaliativas em nossa realidade e inspirar outros pesquisadores, colaborando para a expansão do conhecimento acerca da avaliação no campo educacional brasileiro.

Palavras-chave: Avaliação no ensino superior. Avaliação institucional. Revisão bibliográfica.

Ten years of institutional evaluation (2006 - 2016): what the production of knowledge shows us

Abstract: The present article is the product of a bibliographic review that had as its objective to identify relevant aspects of Brazilian scientific production about institutional evaluation, from 2006 to 2016, in seven periodicals of the educational area with recognized relevance. The results demonstrated that the theme institutional evaluation is being contemplated in various periodicals, with a considerable number of articles and with various approaches. The proposal is to bring elements that contribute with the understanding of evaluative practices in our reality and to inspire other researchers, collaborating to the expansion of the knowledge about the evaluation in Brazilian educational field.

Key words: College evaluation. Institutional evaluation. Bibliographic review. 


\title{
Introdução
}

Já há bastante tempo o tema da avaliação vem ganhando cada vez mais espaço nos debates a respeito da Educação. Isso se deve a avaliação ser um item inerente a todo processo educacional, em todos os níveis de ensino, podendo inclusive modificar os rumos das políticas públicas destinadas ao aprimoramento da Educação. "O campo da avaliação, desde sua constituição, está em permanente mutação, embora nas últimas décadas venha sendo particularmente desafiado, nos âmbitos teórico-metodológicos e práticos, por acontecimentos e mudanças globais, nacionais e locais" (ESTEBAN; AFONSO, 2010, p. 9).

Pensando na importância da avaliação, a discussão apresentada no presente artigo decorre dos trabalhos que os integrantes do Grupo de Estudos e Pesquisa sobre Linguagem, Ensino e Narrativa de professores (GEPLENP- UNESP/Assis) vem realizando há quatro anos sobre a avaliação das aprendizagens no Ensino Superior.

\begin{abstract}
Pensar em avaliação da educação superior nos permite vislumbrar diferentes concepções como diagnóstico, medida, julgamento, regulação da qualidade. Ou ainda, um conjunto de processos complementares, formativos e por vezes somativos, que podem induzir negociações, transformações, ressignificar a vida acadêmica, num movimento contínuo capaz de potencializar o desenvolvimento de uma instituição, melhor posto, da comunidade que a compõe em sua globalidade (COSTA; RIBEIRO; VIEIRA, 2010, p. 87).
\end{abstract}

Para realização dos trabalhos do grupo, financiadas pela FAPESP, diversas fontes foram consultadas, entre elas: livros, artigos e teses, além de serem realizadas aplicação de questionários e entrevistas com discentes e docentes da UNESP/Assis. No presente trabalho damos especial atenção à revisão bibliográfica que realizamos a respeito da avaliação institucional no Ensino superior, no período que engloba os anos 2006 a 2016.

A partir de 2004, a Avaliação Institucional passou a ser uma exigência do Governo Federal, por meio da Lei $\mathrm{n}^{\circ} 10.861$, de 14/04/04, que implantou o Sistema Nacional de Avaliação da Educação Superior - SINAES. O SINAES é parte de uma política de governo voltada à Avaliação da Educação Superior, e obrigatório em todas as instituições de ensino superior do país. É um sistema de avaliação global e integrado das atividades institucionais, composto por: Avaliação das Instituições de Educação Superior (AVALIES), Avaliação dos Cursos de Graduação (ACG), Avaliação do Desempenho dos Estudantes (ENADE).

\footnotetext{
O SINAES foi concebido a partir de um conceito de avaliação baseado nas ideias de integração e participação. No que diz respeito à integração, a proposta inicial do SINAES buscava "assegurar, entre outras coisas, a integração das dimensões internas e externas, particular e global, somativo e formativo, quantitativo e qualitativo e os diversos objetos e objetivos da avaliação" (SINAES, 2004, p. 84). Quanto à participação, a proposta destaca "a exigência ética própria dos processos educacionais, conclama todos os agentes [...] a se envolverem nos processos avaliativos" (SINAES, 2004, p. 84). Composto por três processos, a avaliação dos cursos de graduação, a avaliação institucional e a avaliação do desempenho dos estudantes, o
} 
sistema é alimentado por diferentes agentes: a avaliação dos cursos, realizada por comissões de especialistas ad hoc especialmente constituídas pelo INEP para esta finalidade; a avaliação do desempenho dos estudantes, realizada por estudantes ingressantes e concluintes dos cursos de graduação; e a avaliação institucional, que é composta por dois processos avaliativos: autoavaliação, realizada pela comissão própria de avaliação, constituída por membros da própria instituição e representante da sociedade civil organizada e, a avaliação externa, realizada por comissões de especialistas ad hoc constituídas pelo INEP (RIBEIRO, 2015, p. 144).

Embora se possa observar que o SINAES trouxe alguns avanços para a organização das instituições de ensino superior, é preciso sempre ficar atento. Catani e Gallego (2009), apontam:

Na percepção dos estudiosos que se dedicam ao exame das avaliações externas e institucionais é problemático seu caráter essencialmente quantitativo. No ensino superior, restringem-se à identificação de dimensões mais visíveis e de fácil descrição como medidas físicas, área construída, titulação dos professores, descrição do corpos docente, discente e de servidores, dos produtos, das formaturas, etc. desprezando-se sua diversidade, a identidade que torna única cada instituição bem como as condições específicas e a história que constroem distintas relações de produção e compromisso sociais (DIAS SOBRINHO 1996 apud CATANI; GALLEGO, 2009, p. 57).

O período de estudo escolhido está relacionado com o projeto desenvolvido pelo GEPLENP e foi determinado, por pensarmos que após dois anos da instituição legal, já teríamos acesso a muitos trabalhos que tratam do tema, além disso, uma década também fornece uma organização de material que pode ser considerada significativa. Além disso:

[...] na década de 2000, destaca-se o surgimento de estudos centrados na produção científica divulgada nas principais revistas científicas brasileiras no campo da avaliação educacional, reflexo do acentuado volume de produção científica produzida na tentativa de compreender as experiências implantadas no Brasil a partir da década de noventa. (CALDERÓN; BORGES, 2013, p. 180).

De forma intencional, não selecionamos apenas revistas científicas específicas que tratam especificamente sobre avaliação, pois nosso interesse era observar como tal tema tem sido discutido também em revistas que, de diversas maneiras, tratam do assunto Educação. Foram encontrados 65 artigos que apresentavam o descritor avaliação institucional. Esses artigos tratam de diversos temas relacionados à avaliação institucional e que analisaremos no corpo do trabalho.

Ao realizarmos este trabalho, intencionamos produzir um material que possa demonstrar o que está sendo produzido sobre o tema, buscando conhecer os aspectos que vêm sendo privilegiados nas discussões acadêmicas com vistas a melhor compreender o que se relaciona com a avaliação institucional. Para Soares (1989, p. 3), “essa compreensão do estado de conhecimento sobre um tema, em determinado momento, é necessária no processo de evolução da ciência, a fim de que se ordene periodicamente o conjunto de informações e resultados já obtidos". 
Observou-se, a partir desse levantamento e das leituras de outros artigos que também apresentam estudos do estado da arte em avaliação (TREVISAN; SARTURI, 2016, MINHOTO, 2015, CALDERÓN; BORGES, 2013), que nos últimos anos a produção científica no Brasil tem se avolumado e mostra um interesse bastante relevante a respeito da avaliação institucional.

As publicações analisadas foram as revistas: Avaliação (Campinas; Sorocaba) (33 ocorrências), Cadernos Cedes (2 ocorrências), Educação e Pesquisa (3 ocorrências), Estudos em Avaliação Educacional (16 ocorrências), Educação \& Sociedade (2 ocorrências), Educação \& Realidade (1 ocorrências), Ensaio: Avaliação e Politicas Públicas em Educação (8 ocorrências).

Os periódicos com o maior número de artigos com o descritor avaliação institucional são Avaliação e Ensaio: Avaliação e Políticas Públicas em Educação. Este já era um resultado esperado, já que estes periódicos tem como tema principal a avaliação. Embora já esperássemos esse resultado, pensamos ser importante considerar o que está sendo produzido em outros importantes periódicos da área educacional, pois isso pode dar um panorama mais amplo para nossos estudos.

Para realização desta pesquisa, utilizou-se a abordagem qualitativa por meio da revisão bibliográfica dos periódicos acadêmicos. No primeiro momento de nossa investigação, conforme dito, o estudo deu-se a partir das palavras-chave apresentadas nos artigos. A escolha pelas palavras-chave dá-se por serem elas que demonstram, aos pesquisadores, num primeiro contato com os textos, as ideias e os temas de especial importância para servir de referência às pesquisas. Em seguida, após selecionarmos os textos, passamos à leitura dos resumos, para ter uma ideia melhor do que tratavam, qual a abordagem metodológica utilizada e quais os principais resultados apontados. Em uma última etapa, foi realizada a leitura integral dos textos a fim de conhecer as discussões ali apresentadas.

\section{O material pesquisado}

A análise do material nos proporcionou observar que muitos são os temas relacionados com a avaliação institucional. Abaixo apresentamos os artigos pesquisados ${ }^{1}$, divididos em categorias, em seguida partimos para a análise.

\footnotetext{
${ }^{1}$ A referência completa dos artigos encontra-se ao final do texto. Optamos por organizá-los em ordem cronológica e não em ordem alfabética.
} 
Avaliação institucional e formação de professores: Brasil et al., 2007; Sordi; Ludki, 2009; Souza-Pereira; Leite, 2016.

Avaliação institucional: Comissão Própria de Avaliação e Autoavaliação: Augusto; Balzan, 2007; Peixoto, 2009; Lehfeld et al., 2010; Reis et al., 2010; Sordi, 2011; Bernardes; Rothen, 2015; Nunes, 2006; Rocha, 2006; Grego et al., 2007; Gimenes, 2007; Sousa; Marcondes; Acosta, 2008; Oliver, 2010; Gama, 2010; Afonso, 2010; décia; Argolo, 2010; Costa et al.., 2010; Maba; Marinho, 2012; Ribeiro, 2015; Martins; Coutinho, 2013; Andriola; Oliveira, 2015; Mendes et al., 2015; Espírito Santo; Travassos; Caribe, 2016; Falleiros; Pimenta; Valadão Jr. 2016; Bastos; Rovaris, 2016; Kozen; Adams, 2016.

Avaliação institucional e representações e percepções: Leite et al.. 2007; Alberto; Balzan, 2008; Palazzo; Gomes, 2009; Andriola; Souza, 2010; Santos, Sadala; Borges, 2012.

Avaliação Institucional e SINAES: Polidori; Marinho-Araujo; Barreyro, 2006; Rocha, 2006; Sousa, 2006; Aguiar; Canen, 2007; Polidori; Fonseca; LARROSA, 2007; Abreu Jr. 2009; Vieira; Freitas, 2010; Griboski, 2012; Lacerda, 2015; Ribeiro, 2012; Pinto; Mello; Melo, 2016. Avaliação institucional ao longo do tempo: críticas e considerações: Gatti, 2006; Lindo, 2007; Schlickmann; Alperstedt, 2008; Costa; Ribeiro; Vieira, 2010; Ribeiro, 2011; Rothen; Barreyro, 2011; Herles; Cordorena; Pereira, 2011; Silva; Mendes, 2012; Pfeifer, 2012.

Avaliação institucional e mudança curricular: Mourão et al., 2007; Costa; Bara; Garcia, 2013; Soprano, 2014.

Avaliação institucional e evasão: Andriola et al., 2006; Santos; Lopes, 2011.

Avaliação institucional e pós-graduação: Novaes; Musse, 2008; Minhoto, 2015.

Avaliação institucional e Índice Geral de Cursos: Hoffmann et al., 2014.

\section{O que dizem os artigos}

Como se pode observar no levantamento acima, são muitos os temas relacionados à avaliação institucional (AI). Neste momento empreendemos uma discussão para tentar compreender o que uma década de produção de conhecimento a respeito da avaliação institucional tem a nos mostrar.

Com relação à categoria AI e formação professores, os três artigos, de maneira geral, destacam a importância de se sistematizar e discutir as questões sobre avaliação durante os processos de formação na universidade, já que esta é uma realidade que irá acompanhar os docentes durante toda sua prática. O texto de Brasil et al. (2007), propõe uma reflexão a respeito da AI nos processos de formação docente e também ressalta que muitas vezes o tempo escasso 
e a falta de uma verdadeira sistematização para que se aprofundem os estudos referentes à avaliação prejudicam os processos avaliativos.

$\mathrm{Na}$ pesquisa que realizamos, foram encontrados 25 artigos que tratam das autoavaliações, seis deles (AUGUSTO; BALZAN, 2007; PEIXOTO, 2009; LEHFELD et al., 2010; REIS et al. 2010; SORDI, 2011; BERNARDES; ROTHEN, 2015), especificamente, se referem às Comissões Próprias de Avaliação (CPA).

A existência de uma Comissão Própria de Avaliação (CPA) é exigência legal (Lei n 10.861/2004). A CPA é responsável por conduzir processos internos de avaliação da instituição a fim de contribuir para a melhoria institucional. Além de ser um dos pré-requisitos do Ministério da Educação (MEC) que compõem o Sistema de Avaliação do Ensino Superior (SINAES) para autorização, reconhecimento de cursos e recredenciamento institucional.

O artigo de Augusto e Balzan (2007), por exemplo, destaca o papel dos coordenadores com relação à organização da CPA e dos processos de avaliação de instituições de Campinas/SP. Destacam o papel fundamental deste agente nos processos que avaliam internamente as instituições.

Um dos artigos, Sordi (2011), reflete sobre uma experiência realizada em uma escola pública municipal, em que foi criada uma CPA nos moldes das presentes nas universidades. A autora ressalta que os resultados confirmam a importância da CPA como instância que promove o encontro dos atores sociais nos espaços coletivos para buscarem o aprimoramento da qualidade de ensino de forma organizada e plural.

Os seis artigos pesquisados apontam para a relevância das CPA's, mas também destacam as dificuldades de se realizar um trabalho no âmbito da universidade que traga verdadeiras melhorias, Lehfeld et al. (2010, p. 192) destacam:

\footnotetext{
Apesar de todo o impacto da autoavaliação em termos de autoconhecimento, reconhecimento de potencialidades e dificuldades e, principalmente, dos avanços efetivos promovidos por esse processo, observa-se que para efeito do conceito final da instituição divulgado na mídia, e a consequente imagem pública da IES, todo o trabalho desenvolvido pela CPA em termos de avaliação institucional não é apropriadamente considerado nessa nova orientação dada ao SINAES.
}

Os artigos restantes deste item tratam da autoavaliação de diversas formas. O número de artigos encontrados demonstra que existe uma preocupação muito grande com a questão da autoavaliação. Essa preocupação com a autoavaliação que aparece na quantidade de trabalhos produzidos pode acontecer, pois, pelo menos em tese, esse é um dos momentos mais relevantes (GALDINO, 2011, QUEIROZ, 2011, MABA; MARINHO, 2012) de um processo avaliativo, já que pode fornecer um diagnóstico bastante próximo do real. 
Um dos artigos estudados, Sousa, Marcondes e Acosta (2008), apresenta um trabalho em que as autoras fazem uma espécie de histórico da implantação do processo de autoavaliação na PUC/SP, as autoras afirmam que seu objetivo foi o de possibilitar que a universidade se conscientizasse de seu projeto pedagógico e oferecer subsídios para o aperfeiçoamento das decisões que poderiam reafirmar a identidade social da instituição, assumindo a perspectiva de avaliação formativa. Em seu texto, destacam:

\begin{abstract}
A auto-avaliação de uma Instituição de Ensino Superior (IES) é um processo longo e desafiante, porque implica que ela não se sinta ameaçada com a avaliação, e que os professores, funcionários e gestores dos diferentes níveis administrativos se conscientizem da importância de tomar decisões com base nos resultados que serão apresentados. Na verdade, uma das formas mais simples de escamotear um processo avaliativo, tornando-o inócuo, é não conduzi-lo à tomada de decisões (SOUSA; MARCONDES; ACOSTA, 2008, p. 31).
\end{abstract}

Destacamos o texto de Espírito Santo, Travassos e Caribe (2016). Os autores apresentam uma análise sobre o processo de autoavaliação em 14 faculdades privadas da Bahia, os resultados demonstram que menos da metade das instituições pesquisadas atendem aos requisitos mínimos indicados pelo INEP para a autoavaliação.

Já Falleiros, Pimenta e Valadão Jr. (2016), produzem um artigo em que discutem quais são os significados da autoavaliação para os servidores técnico-administrativos da Universidade Federal de Uberlândia. Os autores apontam que ainda não existe uma cultura da avaliação e que isso pode decorrer da falta de resultados práticos advindos do processo de avaliação.

Também encontramos artigos que mostram de forma bastante clara de que maneira esses processos AI interferem na condução dos processos das organizações. Ribeiro (2015), por exemplo, produz um trabalho de identificação dos processos de autoavaliação em duas universidades - uma pública e uma privada - e conclui que, na IES privada, os resultados da AI impactam de forma mais incisiva no aspecto relacionamento professor $\mathrm{X}$ aluno e, na IES pública, o impacto foi na alteração da condução da aula.

Os artigos encontrados nesta categoria discutem, de maneira geral, os limites e as possibilidades da autoavaliação. O que percebemos é que a autoavaliação tem sido uma preocupação constante dos pesquisadores da Educação que procuram mostrar de que forma ela tem sido utilizada e como os resultados tem sido utilizados pelas próprias instituições.

$\mathrm{Na}$ categoria AI e representações e percepções, encontramos artigos que procuram compreender de que forma os diversos agentes das instituições universitárias pensam os processos de avaliação. O texto de Santos, Sadala e Borges (2012), faz uma reflexão sobre a questão do processo de AI nas instituições brasileiras de ensino superior, tendo como base a teoria psicanalítica e como particular enfoque, a resistência dos atores-sujeitos ao processo e à implantação da cultura de avaliação. 
Evidenciamos também o texto de Alberto e Balzan (2008), que procuram demonstrar que os funcionários das universidades são pouco valorizados nos processos de avaliação, suas percepções a respeito dos processos que regem a universidade nem sempre são levados em consideração. Os autores indicam que há baixo protagonismo dos funcionários (corpo técnicoadministrativo) na construção do projeto político-pedagógico. Também pensando em funcionários técnico-administrativos e gestores e suas representações encontramos o texto de Andriola e Souza (2010), que teve como objetivo analisar a cultura avaliativa na Universidade Federal do Ceará (UFC), tendo como base as representações sociais dos gestores e dos técnicoadministrativos das nove unidades acadêmicas dos campi de Fortaleza.

Já o texto de Leite et al. (2007), trata da percepção dos estudantes sobre avaliação das universidades brasileiras e portuguesas. Segundo os autores:

\begin{abstract}
Para os alunos brasileiros, a avaliação parece ter sentido de avaliação institucional. Para os estudantes portugueses, a avaliação parece ter um significado de avaliação institucional e da aprendizagem. As culturas estudantis de repúdio à avaliação única de uma prova nacional, no caso brasileiro, parecem ter influenciado suas percepções sobre formatos avaliativos. As culturas estudantis relativas à competitividade do mercado, no caso português, valorizaram a avaliação como regulação. Em ambos os casos, os estudantes destacaram tanto a legitimidade da avaliação para a sociedade e os sistemas educativos (cultura englobante) quanto para o cotidiano das universidades (cultura englobada) (p. 661).
\end{abstract}

$\mathrm{Na}$ categoria AI e SINAES, encontramos artigos que tratam do SINAES de maneira ampla. Ao fazer a leitura destes artigos podemos entender os processos que levaram à implementação do sistema de AI das IES, além de observar todas as questões que estão implicadas nesse processo bastante recente na Educação Brasileira.

Em relação a esse aspecto, encontramos em nosso levantamento o artigo de Lacerda (2015) que investiga os pressupostos epistemológicos que nortearam o SINAES. O autor examina a dualidade existente entre os princípios propostos e a sua real efetivação, argumentando sobre a insatisfação da comunidade acadêmica que nem sempre está de acordo com os processos avaliativos implementados.

Já o artigo de Polidori, Marinho-Araújo e Barreyro (2006), realiza um histórico da avaliação institucional desde as primeiras experiências com o PAIUB, implementado em 1994, passando pelo PROVÃO até chegar ao SINAES. O trabalho recupera essas experiências e traz subsídios sobre a construção e a implantação do Sistema de Avaliação da Educação Superior Brasileiro - SINAES, sancionado em 2004, discutindo os desafios e perspectivas decorrentes de sua implementação.

Podemos perceber que nos artigos desta categoria existe uma preocupação com a efetivação do sistema avaliativo e as suas repercussões nas instituições. Além disso, há artigos que nos fazem refletir sobre os desafios e as possibilidades de um sistema que procura contribuir 
com o desenvolvimento do Ensino Superior. Sobre esta questão destacamos o texto de Ribeiro (2015) que tem como objetivo apresentar o modelo de avaliação do SINAES, apontando as dificuldades e facilidades encontradas pelas IES para sua implementação. Para o autor, a principal crítica se coloca em relação às duas finalidades distintas do SINAES, que sejam: aperfeiçoar e desenvolver as instituições, por um lado e a regulação por outro:

O SINAES, em função dos seus objetivos e finalidades, conjuga os dois modelos de avaliação: a avaliação formativa, de caráter educativo, com o intuito de radiografar o funcionamento da IES, apontando os seus pontos fortes e fracos, permitindo, assim, o aprimoramento contínuo do seu trabalho; e a avaliação regulatória, ou somativa, com o intuito de verificar as condições de funcionamento da IES, exigindo um padrão mínimo de qualidade para a sua permanência no Sistema Federal de Ensino Superior. Este parece ser o grande desafio do SINAES. Conjugar estas duas funções num mesmo sistema de avaliação, envolvendo avaliadores e avaliados, representantes de mantenedores, de docentes/técnicos administrativos e discentes e, principalmente, envolvendo avaliadores com posturas diferentes a depender do tipo de avaliação que realizam: ora estão numa posição de examinar as condições de organização e funcionamento da instituição, contribuindo, assim, com a sua evolução qualitativa, ora estão numa posição de fiscalização, verificando se as condições preconizadas pela instituição existem e são efetivas (RIBEIRO, 2015, p. 159).

Com relação à $\mathrm{AI}$ ao longo do tempo: críticas e epistemologia, os textos vão mostrar de que forma a AI foi sendo constituída ao longo dos anos e também trazem críticas ao modelo que vem sendo implementado.

O texto de Costa, Ribeiro e Vieira (2010), por exemplo, apresenta um histórico da AI na Universidade Federal de Goiás, que vai desde a implementação do Programa de Avaliação Institucional das Universidades Brasileiras (PAIUB) em 1994 até o momento atual. As autoras destacam que esse processo ao longo do tempo tem provocado uma mudança na cultura de avaliação e destacam "que esta mudança de cultura deve ser feita articulando processos normativos com processos educativos de mudança também de mentalidade, daqueles que constituem a comunidade acadêmica" (2010, p. 107).

O artigo de Schlickmann, Melo e Alperstedt (2008), também destaca os processos da AI ao longo das últimas décadas evidenciando que que os modelos de $\mathrm{AI}$ ao longo dos governos apresentaram diferentes enfoques institucionais, sendo que houve uma predominância dos enfoques regulador e normativo, embora o cognitivo seja o que permeia o atual sistema de avaliação institucional brasileiro.

O texto de Pfeifer (2012) apresenta um resgate e das concepções que envolvem a avaliação no âmbito das Políticas para a Educação Superior, explicitando as conceituações dicotômicas encontradas na literatura especializada. A autora aponta que:

[...] mesmo voltadas à garantia da qualidade da Educação Superior, as diferentes concepções e modos de operacionalização da Avaliação implicam na construção de culturas acadêmicas igualmente distintas, as quais têm rebatimentos no cotidiano do trabalho docente, da gestão 
institucional e nas definições relativas ao ensino, pesquisa e extensão e à Educação de modo geral (p. 362).

Com relação aos artigos que propõem um olhar crítico aos modelos de AI, destacamos as contribuições de Herles, Condorena e Pereira (2011), que apresentam uma discussão em que apontam a não neutralidade das avaliações de qualidade das universidades. Já o artigo de Gatti (2006) discute de modo crítico, o modelo amplamente utilizado na avaliação institucional como um survey que gera dados quantitativos, analisados em relação a padrões pré-estabelecidos. Ressalta, ainda, que os procedimentos, nessas avaliações institucionais, têm um caráter muitas vezes genérico, os quais limitam os objetivos da própria avaliação, por gerarem valores numéricos que nem sempre refletem a múltipla realidade das universidades. Encerrando suas discussões, Gatti enfatiza (2006, p. 13):

\begin{abstract}
As ideias aqui expostas sinalizam que não é trivial a condução de uma avaliação institucional, e, assim, ela demanda boa preparação dos avaliadores, que, para além do domínio das técnicas básicas da investigação avaliativa, precisam deter certo domínio sobre as condições de construção dinâmica de processos socioculturais, científicos e pedagógicos, com os múltiplos fatores que os interseccionam. Aos avaliadores se pede, atualmente, modos de atuar menos "burocráticos", para abrirem-se às posturas dialógicas; a sistemas de trocas e construção de consensos; à lida democrática com o dissenso; à busca de compreensões quanto aos processos desencadeados, a partir de aportes significativos de vários campos disciplinares, da estatística à antropologia cultural. O desafio na construção dessa nova forma de constituição de processos avaliativos é grande, mas sinaliza um horizonte bem diferente para seus frutos.
\end{abstract}

No geral, os artigos estudados nesta categoria trazem históricos a respeito da AI e mostram formas críticas de se pensá-la, destacando a questão das dificuldades em se realizar a AI sem cair apenas na regulação e monitoramento, apresentam também possibilidades de utilizar os resultados das AI’s para se repensar os rumos da Instituição avaliada.

$\mathrm{Na}$ categoria AI e mudança curricular foram encontrados três artigos (MOURÃO et al., 2007; COSTA; BARA; GARCIA, 2013; SOPRANO, 2014). Esses artigos nos mostram como os resultados da AI podem influenciar as discussões para as mudanças no currículo das instituições. Como exemplo dessa preocupação em repensar o currículo a partir dos resultados das AI's sublinhamos o artigo de Costa, Bara e Garcia (2013), nele as autoras demonstram de que forma o curso de Farmácia da Universidade Federal de Goiás considerando concepções e enfoques de estudantes, professores, servidores técnico-administrativos e especialistas em avaliação, foi possível vislumbrar mudanças que progressivamente vêm permeando o curso.

A categoria AI e pós-graduação tem dois artigos aqui apresentados (NOVAES; MUSSE, 2008; MINHOTO, 2015). O artigo de Novaes e Musse (2008) apresenta a trajetória de criação e implementação de um novo processo avaliativo em um programa de pós-graduação lato sensu em Direito. Nesse contexto, as múltiplas variáveis relacionadas ao processo de ensinoaprendizagem foram consideradas na construção de nove instrumentos, que buscam também 
satisfazer os objetivos do projeto mais amplo de avaliação institucional. Já o artigo de Minhoto (2015) apresenta uma revisão bibliográfica evidenciando a produção na área da política educacional, realizada em Programas de Pós-Graduação em Educação brasileiros, com foco na avaliação em larga escala e institucional.

Por fim, na categoria AI e Índice Geral de Cursos (IGC) temos o artigo de Hoffmann et al. (2014) que tem como objetivo analisar o IGC das universidades públicas e privadas das cinco regiões brasileiras, no intuito de caracterizar o desempenho das IES por região e verificar possíveis discrepâncias intra e inter-regionais identificando oportunidades de melhoria. Após vasta análise, os autores concluem que fica evidenciada a superioridade das Universidades Públicas em relação às Privadas, porém destacam:

\begin{abstract}
Destaca-se que, na sua maioria, os itens que compõem o CPC (Conceito Preliminar de Curso) favorecem as universidades públicas quanto à facilidade de atendimento aos requisitos da qualificação do corpo docente e regime de trabalho. Para explicar o desempenho superior referente ao IGC nas universidades públicas, tem-se a ponderação feita por Bittencourt et al. (2010), em estudo realizado sobre os itens que compõem o CPC coletados em 2008. Os autores evidenciaram vantagem para o setor público na maioria dos itens que formam o CPC, sendo somente os aspectos referentes à infraestrutura e organização didático-pedagógica os pontos fortes da categoria privada, em que ambos os itens perfazem apenas $10 \%$ do CPC [...].

Uma possível solução para minimizar tal disparidade seria o aumento da oferta de vagas nos cursos de pós-graduação (mestrado/doutorado), com a finalidade de equilibrar o mercado de trabalho desses profissionais e, assim, propiciar condições das universidades particulares a satisfazer esses requisitos (HOFFMANN et al., 2014, p. 663).
\end{abstract}

\title{
Servir à avaliação ou servir-se dela?
}

Esse trabalho insere-se na perspectiva colocada pelos autores, centrando esforços na tentativa de compreender de que forma o campo da avaliação vem se constituindo no Brasil e buscando contribuir com novos trabalhos que venham a ser realizados. Conforme podemos observar a produção teórica a respeito da AI nas Instituições de Ensino Superior apresenta um considerável número de artigos produzidos nos últimos dez anos. Esse fato pode decorrer de preocupações com os rumos que o Ensino Superior vem tomando a partir de resultados que são apontados na AI. Além disso, o conceito de avaliação tem se transformando nas últimas décadas devido as maiores preocupações com os resultados e a qualidade da educação. O reflexo disso está na grande quantidade de material produzido sobre esse assunto.

As categorias que apresentam um maior número de contribuições são AI e autoavaliação e AI e SINAES. Com relação à autoavaliação isso pode decorrer do fato de ser um processo que apresenta muitas possibilidades para a construção e reconstrução dos sentidos e significados do Ensino Superior, assim “o diagnóstico decorrente da autorreflexão institucional servirá de espelho para a indicação de soluções para a conservação ou modificação dos rumos da IES, considerando seus objetivos e metas, com base na sua missão" (GALDINO, 2011). Enquanto 
alguns artigos mostram que a autoavaliação ainda apresenta, muitas vezes, resultados aquém dos esperados, outros já apresentam resultados bastante positivos nas IES que realmente levam a sério os processos autoavaliativos e que envolvem de maneira equivalente todos os membros da instituição.

Também pensando nas pessoas que compõem o conjunto das IES, selecionamos os textos da categoria AI: representações e percepções. O resultado da pesquisa nos apresenta uma realidade ainda bastante longe do ideal. Podemos perceber pelas leituras realizadas que muitos dos funcionários que são fundamentais para o funcionamento das instituições ainda são pouco levados em consideração. Situação que precisa ser repensada, já que todos acabam sendo responsáveis pela busca de qualidade tão apregoada pelos discursos correntes.

Já com relação à AI e SINAES também era de se esperar que tivéssemos contato com muitos artigos, já que o SINAES engloba uma série de processos e é utilizado na maioria das IES. O que observamos ao ler estes artigos é uma preocupação com dois pontos principais: as dificuldades de implementação do sistema e o possível uso regulador dos resultados conseguidos. Ao pensar no tempo histórico podemos perceber que esta é ainda uma prática bastante recente na Educação brasileira, o que pode explicar os desajustes que ainda são encontrados. A produção de conhecimento nos mostra que ainda temos um caminho bastante longo a ser percorrido para que as AI's funcionem como uma possibilidade de repensar os rumos da Educação Superior.

Considerando as outras categorias aqui elencadas percebemos que a AI tem adquirido grande importância nos contextos universitários, como indicam os artigos que apontam mudanças curriculares nas IES a partir de resultados obtidos. Também ressaltamos, a partir das leituras empreendidas, a necessidade de que os processos de avaliação conduzidos pelas IES sejam realmente usados para o aperfeiçoamento das instituições e não apenas como instrumento de regulação e monitoramento que podem apenas servir de instrumentos punitivos para os cursos que de alguma maneira não contemplem os resultados almejados.

Após as análises empreendidas coloca-se a pergunta: o que fazemos quando avaliamos? Proporcionamos que as instituições "sirvam-se" das avaliações ou empurramos as mesmas para servirem a ela? Ao formular assim a questão podemos pensar em diversas ênfases sobre a importância das práticas avaliativas e dos estudos que traduzem como seus resultados são apropriados nos domínios do campo educacional. A questão se impõe também quando queremos compreender as formas de elaboração do conhecimento pedagógico ou ao nos depararmos com a velocidade da substituição de práticas pedagógicas utilizadas em decorrência de resultados de avaliações ou ainda com a servidão e apego constituído por uma adesão 
irrestrita as condições das avaliações em larga escala com o objetivo de extrair consequências para o ensino, legitimar escolhas ou exaltar potencialidades.

A constatação de que estudiosos vem identificando novos objetos, temas e delimitações do que é específico em Educação, como as investigações sobre o fracasso escolar, novos sentidos para a educação das populações menos favorecidas e consequente interesse por pesquisas sobre cultura e metodologias do ensino, nos levou a tentar acompanhar aqui os debates sobre avaliação, pois sabemos que ela ainda se constitui em desafio no âmbito das pesquisas em educação.

\section{Referências}

ALBERTO, J. L. M.; BALZAN, N. C. Avaliação de projeto político-pedagógico pelos funcionários: Espaços e representatividade. Avaliação, Campinas; Sorocaba, SP, v. 13, n. 3, p. 745-770, nov. 2008.

ANDRIOLA, W. B.; SOUZA, L. A. de. Representações sociais dos gestores e dos técnicos das Unidades Acadêmicas da Universidade Federal do Ceará acerca da autoavaliação institucional. Avaliação, Campinas; Sorocaba, SP, v. 15, n. 2, p. 45-72, jul. 2010.

AUGUTO, R.; BALZAN, N. C. A vez e a voz dos coordenadores das CPA's das IES de Campinas que integram os SINAES. Avaliação, Campinas; Sorocaba, SP, v. 12, n. 4, p. $597-$ 622, dez. 2007.

BERNARDES, J. dos S; ROTHEN, J. C. Comissão própria de avaliação: dois lados de uma mesma moeda. Estudos em Avaliação Educacional, São Paulo, v. 26, n. 62, p. 420-446, maio/ago. 2015.

BRASIL, A. R. et al. O processo da avaliação institucional como multiplicador de iniciativas para o aperfeiçoamento docente. Avaliação, Campinas; Sorocaba, SP, v. 12, n. 4, p. 663-684, dez. 2007.

CALDERÓN, Adolfo Ignácio; BORGES, Regilson Maciel. Avaliação Educacional: Uma abordagem à luz das revistas científicas brasileiras. Revista Iberoamericana de Evaluación Educativa, Madri, v. 6, n, 1, 2013.

CATANI, Denice Barbara; GALlEGO, Rita de Cássia. Avaliação. São Paulo, Ed. UNESP, 2009.

COSTA, Eula Maria de Melo Barcelos; RIBEIRO, Célia Maria; VIEIRA, Regina Beatriz. Avaliação em movimento: do PAIUB1 ao PGE2. O caso da Universidade Federal de Goiás. Avaliação, Campinas; Sorocaba, SP, v. 15, n. 3, p. 87-108, nov. 2010.

COSTA, E. M. de M. B.; BARA, M. T. F.; GARCIA, T. A. Momentos de avaliação e movimentos de mudança em um curso de Farmácia. Avaliação, Campinas; Sorocaba, SP, v. 18, n. 3, p. 613-628, nov. 2013

ESPÍRITO SANTO, E. do; TRAVASSOS, X. L.; CARIBÉ, S. O. Análise do nível de implantação do processo de autoavaliação nas faculdades privadas de Salvador, Bahia.

Avaliação, Campinas; Sorocaba, SP, v. 21, n. 1, p. 153-172, mar. 2016. 
ESTEBAN, Maria Teresa; AFONSO, Almerindo Janela. Avaliação: reconfigurações e sentidos na construção de um campo. In: ESTEBAN, M.T.; AFONSO, A. J. (Orgs.). Olhares e interfaces: reflexões críticas sobre a avaliação. São Paulo, Ed. Cortez, 2010. p. 9-14.

FALLEIROS, A. E. de S.; PIMENTA, M. L.; VALADÃO JR., V. M. O significado da autoavaliação institucional na perspectiva de técnicos-administrativos de uma universidade pública. Avaliação, Campinas; Sorocaba, SP, v. 21, n. 2, p. 593-618, jul. 2016.

GALDINO, Mary Neusa Dias. A autoavaliação institucional no ensino superior como instrumento de gestão. Rio de Janeiro: Fundação CESGRANRIO, 2011.

GATTI, B. Avaliação Institucional: processo descritivo, analítico ou reflexivo? Estudos em Avaliação Educacional, São Paulo, v. 17, n. 34, p.7-14, maio/ago. 2006.

HERLES, N. E. V.; CONDORENA, E. G. B.; PEREIRA, E. M. de A. La no neutralidade em la evaluacion de la calidad y modelos de evaluación de la educación superior. Casos de Colombia, Argentina y Brasil. Avaliação, Campinas; Sorocaba, SP, v. 16, n. 2, p. 291-316, jul. 2011.

HOFFMANN, Celina et al. O desempenho das universidades brasileiras na perspectiva do Índice Geral de Cursos (IGC). Educ. Pesqui, São Paulo, v. 40, n. 3, p. 651-666, jul./set. 2014.

LACERDA, L. L. V. de. SINAES, teoria e prática: pressupostos epistemológicos em oposição. Avaliação, Campinas; Sorocaba, SP, v. 20, n. 1, p. 87-104, mar. 2015.

LEHFELD, Neide Aparecida de Souza et al. Reflexões sobre o processo de autoavaliação institucional: O olhar de uma comissão própria de avaliação. Avaliação, Campinas; Sorocaba, SP, v. 15, n. 1, p. 177-194, mar. 2010.

LEITE, Denise et al. Estudantes e avaliação da universidade: um estudo conjunto BrasilPortugal. Cadernos de Pesquisa, São Paulo, v. 37, n. 132, p. 661-686, set./dez. 2007.

MABA, Elita Grosch; MARINHO, Sidnei Vieira. A autoavaliação institucional no processo de tomada de decisão em IES: Estudo de caso das Faculdades SENAC/SC. Avaliação, Campinas; Sorocaba, SP, v. 17, n. 2, p. 455-480, jul. 2012.

MINHOTO, Maria Angélica Pedra. Políticas de avaliação em larga escala e institucional: perfil da produção na pós-graduação. Estudos em Avaliação Educacional, São Paulo, v. 26, n. 62, p. 294-324, maio/ago. 2015.

MOURÃO, L. C. et al. Análise institucional e educação: reforma curricular nas universidades pública e privada. Educ. Soc., Campinas, v. 28, n. 98, p. 181-210, jan./abr. 2007

NOVAES, A. de O. N.; MUSSE, L. B. Avaliação Institucional: a busca pela integração dos resultados. Estudos em Avaliação Educacional, São Paulo, v. 19, n. 39, p.9-28, jan./abr. 2008.

PEIXOTO, M. do C. de L. A Avaliação Institucional nas Universidades Federais e as Comissões Próprias de Avaliação. Avaliação, Campinas; Sorocaba, SP, v. 14, n. 1, p. 9-28, mar. 2009.

PFEIFER, Mariana. Dicotomias conceituais da avaliação da educação superior. Avaliação, Campinas; Sorocaba, SP, v. 17, n. 2, p. 351-364, jul. 2012.

POLIDORI, M. M.; MARINHO-ARAUJO, C. M.; BARREYRO, G.B. SINAES: perspectivas e desafios na avaliação da educação superior brasileira. Ensaio, Rio de Janeiro, v. 14, n. 53, p.425-436, 2006. 
QUEIROZ, Kelli Consuêlo Almeida de Lima. Eu avalio, tu avalias, nós nos autoavaliamos?: uma experiência proposta pelo SINAES. Campinas: Autores Associados, 2011.

REIS, C. Z. T. et al. Autoavaliação em um Instituição Federal de Ensino Superior: Resultados e Implicações. Avaliação, Campinas; Sorocaba, SP, v. 15, n. 3, p. 109-129, nov. 2010.

RIBEIRO, Jorge Luís Lordelo de Sales. SINAES: o que aprendemos acerca do modelo adotado para avaliação do ensino superior no Brasil. Avaliação, Campinas; Sorocaba, SP, v. 20, n. 1, p. 143-161, mar. 2015.

SANTOS, E. G.; SADALA, M. da G. S.; BORGES, S. X. de A. Avaliação Institucional: por que os atores silenciam? Educação e Realidade, Porto Alegre, v. 37, n. 2, p. 551 -568, maio/ago. 2012.

SCHLICKMANN, R.; MELO, P. A. de; ALPERSTEDT, G. D. Enfoques da Teoria Institucional nos modelos de Avaliação Institucional Brasileiros. Avaliação, Campinas; Sorocaba, SP, v. 13, n. 1, p. 153-168, mar. 2008.

SOARES, Magda. A alfabetização no Brasil. O estado do conhecimento. Brasília: INEP/MEC, 1989.

SOPRANO, G. Autonomía y heteronomía de la educación militar. Un análisis de los procesos de evaluación institucional en los Institutos Universitarios de Las Fuerzas Armadas Argentinas. Avaliação, Campinas; Sorocaba, SP, v. 19, n. 1, p. 267-289, mar. 2014

SORDI, M. R. Comissão Própria de Avaliação (CPA): similaridades e dessemelhanças no uso da estratégia na Educação Superior e em escolas do Ensino Fundamental. Avaliação, Campinas; Sorocaba, v. 16, n. 3, p. 603-617, nov. 2011.

SOUSA, Clariza Prado; MARCONDES, Anamérica Prado; ACOSTA, Sandra Ferreira. AutoAvaliação Institucional: uma discussão em processo. Estudos em Avaliação Educacional, São Paulo, v. 19, n. 39, jan./abr. 2008.

TREVISAN, Monica de Souza; SARTURI, Rosane Carneiro. O estado da arte do Sinaes: levantamento de teses e conceitos. SIMPÓSIO AVALIAÇÃO DA EDUCAÇÃO SUPERIOR, 2., Porto Alegre, 2016. Anais... Porto Alegre: UFRGS, 2016 


\section{Relação dos artigos consultados}

\begin{tabular}{|l}
\hline Avaliação (Campinas) \\
\hline POLIDORI, M.M.; FONSECA, D. G. da; LARROSA, TARTER S.F.. Avaliação Institucional Participa \\
Avaliação (Campinas) vol.12 no.2, p. 333-348, Sorocaba, Junho 2007. \\
GREGO, S. M. D.; PINHO, S.Z. de; BRÁZ, J.R. C.; OBA, E.; RAPHAEL, H.S.; MATOS, M.C. A \\
Construção do Processo Democrático de Auto-Avaliação Institucional na Unesp. Avaliação \\
(Campinas) vol.12, no. 2 , Sorocaba, , p. 257-289, Junho 2007.
\end{tabular}

PEREZ LINDO, Augusto. La Evaluación y la Universidad Como Objeto de Estudio. Avaliação, (Campinas); Sorocaba, SP, v. 12, n. 4, p. 583-596, dez. 2007.

AUGUTO, R.; BALZAN, N. C. A vez e a voz dos coordenadores das CPA's das IES de Campinas que integram os SINAES. Avaliação (Campinas) ; Sorocaba, SP, v. 12, n. 4, p. 597-622, dez. 2007.

BRASIL, A. R.; BARBOSA, C.I. V.; RODRIGUES, F. de P. M.; BLOIS, M.D.; CUNHA, M. S.da; XAVIER, R. T. O. O processo da avaliação institucional como multiplicador de iniciativas para o aperfeiçoamento docente. Avaliação (Campinas); Sorocaba, SP, v. 12, n. 4, p. 663-684, dez. 2007

SCHLICKMANN, R.; MELO, P. A. de; ALPERSTEDT, G. D.. Enfoques da Teoria Institucional nos modelos de Avaliação Institucional Brasileiros. Avaliação (Campinas) ; Sorocaba, SP, v. 13, n. 1, p. 153-168, mar. 2008.

ALBERTO, J. L. M.; BALZAN, N. C. Avaliação de projeto político-pedagógico pelos funcionários: Espaços e representatividade. Avaliação (Campinas); Sorocaba, SP, v. 13, n. 3, p. 745-770, nov. 2008.

PEIXOTO, M. do C. de L. A Avaliação Institucional nas Universidades Federais e as Comissões Próprias de Avaliação. Avaliação (Campinas) ; Sorocaba, SP, v. 14, n. 1, p. 9-28, mar. 2009.

SORDI, M. R. L. de; LUDKE, M. DA avaliação da aprendizagem à avaliação institucional: Aprendizagens necessárias. Avaliação (Campinas) ; Sorocaba, SP, v. 14, n. 2, p. 253-266, jul. 2009.

LEHFELD, N. A. de S.; GABARRA, M. H. C.; COSTA, C. da; Sousa, SILVA, Y.T. C. Reflexões sobre o processo de autoavaliação institucional: O olhar de uma Comissão Própria de Avaliação. Avaliação (Campinas); Sorocaba, SP, v. 15, n. 1, p. 177-194, mar. 2010.

ANDRIOLA, W. B.; SOUZA, L. A.de. Representações sociais dos gestores e dos técnicos das Unidades Acadêmicas da Universidade Federal do Ceará acerca da autoavaliação institucional. Avaliação (Campinas); Sorocaba, SP, v. 15, n. 2, p. 45-72, jul. 2010.

COSTA, E. M.de M. B.; RIBEIRO C. M.; VIEIRA, R. B. B.. Avaliação em movimento: do PAIUB1 ao PGE2: O caso da Universidade Federal de Goiás. Avaliação (Campinas); Sorocaba, SP, v. 15, n. 3, p. 87-108, nov. 2010.

REIS, C. Z. T.; SILVEIRA, S. de F. R.; FERREIRA, M. A. M. Autoavaliação em um Instituição Federal de Ensino Superior: Resultados e Implicações. Avaliação (Campinas) ; Sorocaba, SP, v. 15, n. 3, p. 109-129, nov. 2010.

PEIXOTO, M. do C. de L. Avaliação Institucional Externa no SINAES: Considerações sobre a prática recente. Avaliação (Campinas); Sorocaba, SP, v. 16, n. 1, p. 11-36, mar. 2011.

RIBEIRO, J.L. L. de S. Avaliação das Universidades Brasileiras: As possibilidades de avaliar e as dificuldades de ser avaliado. Avaliação (Campinas) ; Sorocaba, SP, v. 16, n. 1, p. 57-71, mar. 2011.

ROTHEN, J. C.; BARREYRO, G. B. A “RAIES” e a Revista Avaliação: A construção de um marco teórico, político e metodológico. Avaliação (Campinas) ; Sorocaba, SP, v. 16, n. 2, p. 267-290, jul. 2011. 
HERLES, N. E. V.; CONDORENA, E. G. B.; PEREIRA, E. M. de A.. La no neutralidade em la evaluacion de la calidad y modelos de evaluación de la educación superior. Casos de Colombia, Argentina y Brasil. Avaliação (Campinas) ; Sorocaba, SP, v. 16, n. 2, p. 291-316, jul. 2011.

SANTOS BAGGI, C. A. dos; LOPES, D. A. Evasão e avaliação institucional no Ensino Superior: Uma discussão bibliográfica. Avaliação (Campinas); Sorocaba, SP, v. 16, n. 2, p. 355-374, jul. 2011.

SORDI, M.R. Comissão Própria de Avaliação (CPA): Similaridades e Dessemelhanças no uso da estratégia na Educação Superior e em escolas do Ensino Fundamental. Avaliação (Campinas) ; Sorocaba, SP, v. 16, n. 3, p. 603-617, nov. 2011

SILVA, E. A. da; MENDES, M. da C. B. Avaliação Institucional na Universidade Agostinho Neto (Angola) e regulação estatal. Perspectivas, práticas e desafios. Avaliação (Campinas); Sorocaba, SP, v. 17, n. 2, p. 317 350 , jul. 2012

PFEIFER, M. Dicotomias conceituais da avaliação da Educação Superior. Avaliação (Campinas); Sorocaba, SP, v. 17, n. 2, p. 351-364, jul. 2012

MABA, E. G.; MARINHO, S. V. A autoavaliação institucional no processo de tomada de decisão em IES: Estudo de caso das Faculdades SENAC/SC. Avaliação (Campinas); Sorocaba, SP, v. 17, n. 2, p. 455-480, jul. 2012.

COSTA, E. M. de M. B.; BARA, M. T. F.; GARCIA, T. A. Momentos de avaliação e movimentos de mudança em um curso de Farmácia. Avaliação (Campinas); Sorocaba, SP, v. 18, n. 3, p. 613-628, nov. 2013

SOPRANO, G. Autonomía y heteronomía de la educación militar. Un análisis de los procesos de evaluación institucional en los Institutos Universitarios de Las Fuerzas Armadas Argentinas. Avaliação (Campinas); Sorocaba, SP, v. 19, n. 1, V.20 N.1, p. 267-289 mar. 2014

LACERDA, L. L. V. de. SINAES, teoria e prática: pressupostos epistemológicos em oposição. Avaliação (Campinas); Sorocaba, SP, v. 20, n. 1, p. 87-104, mar. 2015.

RIBEIRO, J. L. L. de S.. SINAES: o que aprendemos acerca do modelo adotado para avaliação do ensino superior no Brasil. Avaliação (Campinas); Sorocaba, SP, v. 20, n. 1, p. 143-161, mar. 2015

ANDRIOLA, W. B.; OLIVEIRA, K. R. B. de. Autoavaliação institucional na Universidade Federal do Ceará (UFC): meio século de história. Avaliação (Campinas); Sorocaba, SP, v. 20, n. 2, p. 489-512, jul. 2015

FRANCISO, T. H. A.; NAKAYAMA, M. K.; MELO, P. A. de; PITTA, M. A.; OLIVEIRA, F. P. de. Análise epistemológica da avaliação institucional da educação superior brasileira: reflexões sobre a transposição de paradigmas. Avaliação (Campinas); Sorocaba, SP, v. 20, n. 2, p. 531-562, jul. 2015

PINTO, R. S; MELO, S. P. T. de; MELO, P. A. Meta-avaliação: uma década do Processo de Avaliação Institucional do SINAES. Avaliação (Campinas); Sorocaba, SP, v. 21, n. 1, p. 89-107, mar. 2016

ESPÍRITO SANTO, E. do; TRAVASSOS, X. L.; CARIBÉ, S. O. Análise do nível de implantação do processo de autoavaliação nas faculdades privadas de Salvador, Bahia . Avaliação (Campinas); Sorocaba, SP, v. 21, n. 1, p. 153-172, mar. 2016

FALLEIROS, A. E. de S.; PIMENTA, M. L.; VALADÃO JR., V. M.. O significado da autoavaliação institucional na perspectiva de técnicos-administrativos de uma universidade pública. Avaliação (Campinas); Sorocaba, SP, v. 21, n. 2, p. 593-618, jul. 2016

BASTOS, C. C. B. C.; ROVARIS, N. A. Z. A relevância do processo de autoavaliação institucional da universidade tecnológica para a configuração do bom professor. Avaliação (Campinas); Sorocaba, SP, v. 21, n. 3 , p. $767-781$, nov. 2016

KONZEN, L. Z.; ADAMS, E. Autoavaliação institucional: um estudo sobre a análise de dados da autoavaliação em perspectiva diacrônica. Avaliação (Campinas); Sorocaba, SP, v. 21, n. 3, p. 783-798, nov. 2016 


\begin{tabular}{|l|}
\hline Cadernos Cedes \\
\hline ABREU JÚNIOR, N. de. Sistemas de Avaliação da Educação Superior Brasileira. Cadernos Cedes. \\
Campinas vol. 29, n. 78, p. 257-269, maio/ago. 2009 \\
$\begin{array}{l}\text { SORDI, M. R. L.; BERTAGNA, R. H.; SILVA, M. M.. A AAvaliação Institucional Participativa e os } \\
\text { espaços políticos de participação construídos, reinventados, conquistados na escola. Cadernos Cedes, } \\
\text { Campinas, v. 36, n. 99, p. 175-192, maio-ago., 2016. }\end{array}$ \\
\hline
\end{tabular}

\section{Educação e Pesquisa}

HOFFMANN C. et al.. O desempenho das universidades brasileiras na perspectiva do Índice Geral de Cursos (IGC). Educ. Pesqui., São Paulo, v. 40, n. 3, p. 651-666, jul./set. 2014.

MENDES, G. do S. C. V. et al.. Autoavaliação como estratégia de resistência à avaliação externa ranqueadora. Educ. Pesqui., São Paulo, v. 41, n. especial, p. 1283-1298, dez., 2015.

LIMA, L. A avaliação institucional como instrumento de racionalização e o retorno à escola como organização formal. Educ. Pesqui., São Paulo, v. 41, n. especial, p. 1339-1352, dez., 2015.

\section{Estudos em Avaliação Educacional}

GATTI, B. Avaliação Institucional: processo descritivo, analítico ou reflexivo?. Estudos em Avaliação Educacional. São Paulo, v. 17, n. 34, p.7-14, maio/ago. 2006.

SOUSA, C.P. Avaliação de Instituições de Ensino Superior: discutindo a necessidade de diretrizes metodológicas e estratégias de implantação. Estudos em Avaliação Educacional. São Paulo, v. 17, n. 35 , p.103-114, set./dez. 2006.

GIMENES, N. Estudo Metavaliativo do Processo de Auto avaliação em uma Instituição de Educação Superior no Brasil. Estudos em Avaliação Educacional. São Paulo, v. 18, n. 37, p. 217-243, maio/ago. 2007.

NOVAES, A. de O. N.; MUSSE, L. B. Avaliação Institucional: a busca pela integração dos resultados. Estudos em Avaliação Educacional. São Paulo, v. 19, n. 39, p.9-28, jan./abr. 2008.

SOUZA, C. P.; MARCONDES, A. P., ACOSTA, S.F. .Auto Avaliação Institucional: uma discussão em processo. Estudos em Avaliação Educacional. São Paulo, v. 19, n. 39, p. 29-48, jan./abr. 2008.

OLIVER, A. C. Avaliação institucional: uso de abordagens diversificadas de pesquisa. Estudos em Avaliação Educacional. São Paulo, v. 21, n. 45, p. 13-32, jan./abr. 2010.

GAMA, Z. Avaliação das instituições públicas de ensino superior: direções e interesses subjacentes. Estudos em Avaliação Educacional. São Paulo, v. 21, n. 45, p. 33-44, jan./abr. 2010.

AFONSO, A. J. Políticas educativas e auto-avaliação da escola pública portuguesa: apontamentos de uma experiência. Estudos em Avaliação Educacional. São Paulo, v. 21, n. 46, p.343-361,2010.

DÉCIA, A.C.M.; ARGOLLO, R. S. N. Autoavaliação institucional da UFBA na era Sinaes: a experiência revisitada na Escola de Administração. Estudos em Avaliação Educacional. São Paulo, v.21, n.46, P.387404, maio/ago. 2010.

RIBEIRO, E. A. Convergências e divergências das práticas de autoavaliação institucional em IES pública e privada na percepção da comunidade acadêmica. Estudos em Avaliação Educacional. São Paulo, v.23, n.51, P.168-188, 2012

GAMAM, Z. Avaliação Institucional: Primeiras aproximações - Teoria e Crítica. Estudos em Avaliação Educacional. São Paulo, v. 23, n. 52, p. 254-272, maio/ago. 2012

GRIBOSKI, C. M. O Enade como indutor da qualidade da educação superior. Estudos em Avaliação Educacional. São Paulo, v. 23, n. 53, p. 178-195, set/dez. 2012. 
MARTINS, M. A. R.; COUTINHO, C. de Q. e S.Coutinho. O corpo técnico--administrativo na autoavaliação institucional. Estudos em Avaliação Educacional. São Paulo, v. 24, n. 54, p. 220-241, jan./abr. 2013

MINHOTO, M. A. P. Políticas de avaliação em larga escala e institucional: perfil da produção na pósgraduação. Estudos em Avaliação Educacional. São Paulo, v. 26, n. 62, p. 294-324, maio/ago. 2015

BERNARDES, J. dos .S; ROTHEN, J. C. Comissão própria de avaliação: dois lados de uma mesma moeda. Estudos em Avaliação Educacional. São Paulo, v. 26, n. 62, p. 420-446, maio/ago. 2015

LEITE, F. S.-P. Avaliação institucional e qualidade educativa na formação inicial de professores em Portugal. Estudos em Avaliação Educacional. São Paulo, v. 27, n. 65, p. 440-466, maio/ago. 2016 .

\section{Educação e Sociedade}

MOURÃO, L. C.; MARTINS, R. de C. B.; VIEIRA, C. M.; ROSSIN, E.; L’ABBATE, S. Análise institucional e educação: reforma curricular nas universidades pública e privada. Educ. Soc. Campinas, vol. 28, n. 98, p. 181-210, jan./abr. 2007.

SORDI, M.R. L. de. Implicações ético-epistemológicas da negociação nos processos de avaliação institucional participativa. Educ. Soc. [online]. Campinas, vol.33, n.119, pp.485-510, 2007.

Educação e Realidade

SANTOS, E. G.; SADALA, M. da G. S.; BORGES, S. X. de A. Avaliação Institucional: por que os atores silenciam? Educação e Realidade. Porto Alegre, v. 37, n. 2, p. 551 -568, maio/ago. 2012.

\section{Ensaio: Avaliação e Politicas Públicas em Educação}

NUNES, L. C. As dimensões da auto-avaliação institucional: tecendo redes de redes. Ensaio: aval.pol.públ.Educ. [online]. Rio de Janeiro, vol.14, n.52, pp.339-348, 2006.

ANDRIOLA, W. B.; ANDRIOLA, C. G.; MOURA, C. P. Opiniões de docentes e de coordenadores acerca do fenômeno da evasão discente dos cursos de graduação da Universidade Federal do Ceará (UFC). Ensaio: aval.pol.públ.Educ.[online]., Rio de Janeiro, vol.14, n.52, pp.365-382, 2006.

POLIDORI, M. M.; MARINHO-ARAUJO, C. M. ; BARREYRO, G.B. SINAES: perspectivas e desafios na avaliação da educação superior brasileira. Ensaio: aval.pol.públ.Educ. [online]., Rio de Janeiro, vol.14, n.53, pp.425-436, 2006.

ROCHA, N. M. F. Auto-avaliação de centros de pós-graduação: uma proposta em ação. Ensaio: aval.pol.públ.Educ. [online]., Rio de Janeiro, vol.14, n.53, pp.487-506, 2006.

AGUIAR, N. M. C. B. dE; CANEN, A. Impactos de políticas de avaliação institucional: um estudo de caso no sistema de ensino naval brasileiro. Ensaio: aval.pol.públ.Educ. [online], Rio de Janeiro, vol.15, n.54, pp.53-66, 2007.

PALAZZO, J.; GOMES, C. A. Plano de carreira e avaliação dos professores: encontros e desencontros. Ensaio: aval.pol.públ.Educ. [online]. Rio de Janeiro, vol.17, n.63, pp.205-234, 2009.

VIEIRA, R. L. B.; FREITAS, SIQUEIRA, K. O SINAES na universidade pública estadual: análise do processo de construção da avaliação interna na Universidade do Estado da Bahia (UNEB). Ensaio: aval.pol.públ.Educ. [online]. Rio de Janeiro,vol.18, n.68, pp.443-464, 2010.

GAMA, Z.; VILLARDI, R.1. Espaço comum de Ensino Superior da União Europeia, América Latina e Caribe (ECES - UEALC): nova forma de incorporação dependente?. Ensaio: aval.pol.públ.Educ. [online]. Rio de Janeiro,vol.22,n.85,pp.917-938, 2014. 
${ }^{1}$ Raquel Lazzari Leite Barbosa Universidade Estadual Paulista "Júlio de Mesquita Filho"| Departamento de Educação | Assis| SP | Brasil. Contato: raqueleite@uol.com.br ORCID (iD) 0000-0002-7688-8486

${ }^{2}$ Rosaria Fátima Boldarine Universidade Presbiteriana Mackenzie| Departamento de Educação Continuada | São Paulo | SP | Brasil. Contato: rosariaboldarine@gmail.com ORCID (iD) 0000-0001-8653-2232

Artigo recebido em 30 de outubro de 2017 e aprovado em 2 de abril de 2018. 